\title{
EL DERECHO CONSTITUCIONAL DE PETICIÓN Y SU INSUFICIENTE REGULACIÓN LEGISLATIVA
}

\section{Humberto Nogueira Alcalá*}

RESUMEN: El artículo realiza una delimitación del derecho fundamental de petición en el ordenamiento jurídico nacional, considerando sus fuentes constitucionales y de derecho internacional de los derechos humanos, centrando su análisis en la insuficiente regulación de desarrollo legislativo de dicho derecho, fuera del ámbito propiamente del gobierno y la administración.

PALABRAS ClaVE: Derecho fundamental de petición - Delimitación del derecho - Límites o fronteras del derecho - Regulación del derecho.

\section{The Constitutional Right to Petition AND ItS POOR LEGISLATIVE REGULATION}

ABSTRACT: The article defines the fundamental right to petition in the Chilean legal system, considering its constitutional and Human Rights International Law sources, and focuses in the analysis of its poor regulation of the legislative development of said right, outside of the specific field of the government and its agencies.

KEY WORDS: Fundamental right to petition - Delimitation of the law - Borders or frontiers of the law - Regulation of the law.

\section{INTRODUCCIÓN}

El derecho de petición históricamente ha tenido gran importancia, apareciendo en las principales declaraciones de derechos de los siglos XVII y XVIII, como son el "Bill of Rights" inglés del 13 de febrero de 1689 , en su punto VI, que asegura a los súbditos el derecho de petición

\footnotetext{
El autor es Doctor en Derecho por la Universidad Católica de Lovaina La Nueva. Profesor Titular de Derecho Constitucional y Director del Centro de Estudios Constitucionales de Chile de la Universidad de Talca, Campus Santiago. nogueira@utalca.cl.

Fecha de recepción: 7 de septiembre de 2007.

Fecha de aprobación: 30 de septiembre de 2008.
} 
ante el Rey, considerando ilegal la prisión o procesamiento de los peticionarios. Por otra parte, a Constitución francesa del 3 de septiembre de 1791, en su Título I, proclama como derecho natural, el de dirigir a las autoridades constituidas peticiones individuales. Finalmente, la primera enmienda de la Constitución norteamericana impide al Congreso Nacional la aprobación de leyes que afecten el derecho del pueblo a solicitar reparación a cualquier agravio, asegurando así el derecho de petición ante las autoridades. Dicho derecho fue consignado como parte de los derechos fundamentales por el constitucionalismo decimonónico y permanece en el constitucionalismo del siglo XX e inicios del siglo XXI.

La consideración del derecho fundamental de petición en nuestro ordenamiento jurídico de principios del siglo XXI debemos considerarlo desde los principios de unidad de la Constitución, de eficacia integradora y de efecto útil, dentro de la perspectiva además de irradiación de todo el texto por los valores y principios jurídicos políticos de las bases de la institucionalidad. En efecto, el capítulo de Bases de la Institucionalidad de la Carta Fundamental, en su artículo $1^{\circ}$ precisa una concepción instrumental del Estado, el cual está al servicio de la persona humana y su fin es la construcción del bien común, de allí se deriva su concepción personalista y de servicio a los integrantes de la sociedad chilena. Esta es sin lugar a dudas, una concepción que debe irradiar todo el texto constitucional, como asimismo, iluminar el deber del Estado de respetar y promover los derechos fundamentales que establece el inciso $2^{\circ}$ del artículo $5^{\circ}$ de la Constitución y el deber del Estado de "promover la integración armónica de todos los sectores de la Nación y asegurar el derecho de las personas de participar con igualdad de oportunidades en la vida nacional", determinado en el artículo $1^{\circ}$ inciso final de la Constitución Política de la República.

Otro elemento básico que debe tenerse presente en esta materia es que nos encontramos en una "república democrática", como establece claramente el artículo $4^{\circ}$ de la Carta Fundamental, cuyos valores y principios iluminan también la perspectiva de los derechos fundamentales. Asimismo, nuestra democracia es esencialmente una democracia representativa con escasos mecanismos de participación directa de la ciudadanía, lo que requiere con mayor razón que la autoridad pública, en sus diversos niveles y funciones, esté disponible a recibir las inquietudes, demandas, sugerencias y conocimientos de problemas que sean de su competencia y buscar la forma de acogerlos y resolverlos, en un Estado que "está al servicio de la persona humana", como determina el artículo $1^{\circ}$ en el inicio de su inciso $4^{\circ}$.

Por otra parte, nuestro artículo $5^{\circ}$ inciso segundo de la Constitución, establece a los órganos estatales el deber de respetar y promover el derecho de petición asegurado constitucionalmente, derecho fundamental que, de acuerdo con el artículo $6^{\circ}$ de la Constitución, obliga a todos los titulares o integrantes de los órganos del Estado, los cuales quedan 
vinculados por el derecho y no pueden desconocer su núcleo esencial, como determina el artículo $19 \mathrm{~N}^{\circ} 26$, contenido que incluye el deber de respuesta, sin el cual el derecho de petición se desnaturaliza y pierde todo sentido útil.

Asimismo, en materia constitucional y especialmente de derechos fundamentales, un postulado básico de interpretación constitucional que forma parte integrante de los principios constitucionales mismos de la Constitución material, exige al intérprete constitucional dar a los preceptos de la Carta Fundamental un efecto útil y una interpretación pro persona. Asimismo, el texto constitucional vigente debemos interpretarlo en clave republicana democrática, la que implica una fluida comunicación entre los miembros de la sociedad civil y sus representantes en el gobierno del Estado. En esta materia hay que desechar la perspectiva de la Constitución testamento o arqueológica como método válido de interpretación constitucional, en el sentido de que el Constituyente de 1980, bajo la influencia del informe del Consejo de Estado no habría asegurado el derecho de respuesta frente a las peticiones, ya que esta no está contemplada en el texto constitucional. Al respecto basta establecer la existencia de un cambio radical de contexto político, que implica el paso de un régimen autocrático militar a uno de carácter republicano democrático, para realizar una interpretación de los derechos fundamentales en esta última perspectiva y no en la primera, debiendo realizarla en clave contextual constitucional democrática.

El derecho de petición constituye uno de los derechos menos perfilados de la Carta Fundamental y con una construcción dogmática menos desarrollada, como asimismo, con una insuficiente regulación legal, la que solo se refiere a ámbitos parciales del mismo.

\section{FUENTES DEL DERECHO}

El artículo $19 \mathrm{~N}^{\circ} 14$ de la Constitución precisa como derecho fundamental de las personas:

"El derecho de presentar peticiones a la autoridad, sobre cualquier asunto de interés público o privado, sin otra limitación que la de proceder en términos respetuosos y convenientes".

La Declaración Americana de los Derechos y Deberes del Hombre, en su artículo 24 dispone:

"Toda persona tiene derecho de presentar peticiones respetuosas a cualquier autoridad competente, ya sea por motivos de interés general, ya sea en interés particular, y el de tener pronta resolución". 
El Pacto Internacional de Derechos Civiles y Políticos de Naciones Unidas, en su artículo 25 dispone:

"Todos los ciudadanos gozarán, sin ninguna de las distinciones mencionadas en el artículo 2, y sin restricciones indebidas, de los siguientes derechos y oportunidades:

a) Participar en la dirección de los asuntos públicos, directamente o por medio de representantes libremente elegidos".

La Convención Americana sobre Derechos Humanos, en su artículo 23, establece:

"Derechos politicos.

1. Todos los ciudadanos deben gozar de los siguientes derechos y oportunidades:

a) De participar en la dirección de los asuntos públicos, directamente o por medio de representantes libremente elegidos;

[...]".

\section{Delimitación del derecho}

El derecho a presentar peticiones a la autoridad, constituye un instrumento de participación democrática, posibilitando que las personas pueden presentar o hacer valer sus problemas, necesidades, sugerencias, planteamientos de interés general, requerimientos a toda persona que desempeńe una función de agente de algún órgano u organismo estatal que tenga el carácter de autoridad, en materias que sean del ámbito de su respectiva competencia, constituyendo un derecho residual y complementario de las actividades regladas que operan de cuando al principio de legalidad, dentro del ordenamiento jurídico.

\section{Caracterización del derecho fundamental de petición}

El derecho de petición sobre el cual no hay duda alguna de ser un derecho fundamental, ya que se encuentra asegurado dentro del artículo 19 de la Carta Fundamental, podemos considerarlo como un derecho de libertad que se presenta como de estatus negativo, forma parte de los derechos a la expresión del pensamiento libre ${ }^{1}$, posibilitando la comunicación y el acceso directo de las personas a la autoridad competente para expresarle

Evans de la Cuadra, Enrique (1986). Derechos Constitucionales. Tomo I, Santiago de Chile, p. 28. 
sus necesidades, problemas u observaciones, sin que exista ninguna barrera intermedia.

El derecho en análisis constituye, asimismo, un derecho de participación cívica pero no un derecho político, el que protege intereses no garantizados por otros derechos, siendo en tal sentido también un derecho residual.

No es un derecho político ya que pueden ejercerlo personas que no son ciudadanos ni su objetivo es necesariamente el conseguir fines de interés público, como asimismo, tampoco implica la expresión de la potestad pública, requisitos o elementos indispensables del ejercicio de los derechos políticos. Como señala Spagna Musso, la relación entre la petición y la autoridad a la que la primera va dirigida "no es jurídico ni necesario sino psicológico y eventual" 2 . Asimismo, a través del derecho de petición no se ejerce un estatus activo ciudadano que se da a través del derecho de sufragio, la iniciativa popular de ley, el referéndum abrogatorio u otras formas de democracia semidirecta.

Es un derecho de libertad de estatus negativo, ya que impide los ataques preventivos o represivos que contra él puedan efectuar los poderes públicos, lo que conlleva la obligación del Estado de no impedir la formulación de tales consideraciones a los individuos, el no oponer obstáculos ni impedir el libre ejercicio de las personas a presentar peticiones a la autoridad, como también impide al Estado imponer sanciones por su legítimo uso a los peticionarios. Del ejercicio del derecho de petición no puede derivar perjuicio de ningún tipo para el peticionario, salvo que se incurra en tal ejercicio en falta o delito.

Como ya señalaba Jellinek en la primera mitad del siglo XX, el derecho de petición deriva de la esfera de la libertad y el ejercicio del derecho no puede ser ni prohibido ni castigado ${ }^{3}$.

La dimensión de protección defensiva del derecho de petición tiene especial eficacia en los actos preparatorios necesarios para su ejercicio, especialmente, en su modalidad de petición colectiva. En efecto, en determinados momentos específicos de la vida de una sociedad, determinados problemas o necesidades adquieren una fuerza significativa las cuales dan lugar a peticiones colectivas, cuyos actos preparatorios con el objeto de concitar el mayor apoyo social posible y de movilizar a los firmantes, requiere repartir material informativo, realización de reuniones, recolección de firmas. Todas estas actividades previas a la presentación de la petición se encuentran protegidas por el contenido defensivo inherente a dicho derecho, sin que dichas actividades preparatorias puedan ser obstaculizadas o impedidas por los poderes públicos.

2 Spagna Musso, Enrico (1957). "Note sul diritto di petizione". Rassegna di Diritto Pubblico. Anno XII, Italia, p. 135.

3 Jellinek, Georg (1978). Teoria General del Estado. Buenos Aires, Maipú, p.595. 
El derecho de petición permite que las personas hagan conocer a la autoridad competente respectiva, preocupaciones, necesidades y propuestas expresadas fuera de los recursos administrativos y de los procedimientos legislativos y judiciales formalizados.

El derecho de petición no se confunde con los recursos administrativos formalizados, ya que ellos exigen estar en una relación determinada con la administración pública para poder ejercerlos, existiendo requisitos de legitimación activa que no operan en el ejercicio del primer derecho. Además los recursos administrativos por regla general tienen por objeto modificar o anular actos administrativos, impugnándolos de acuerdo al procedimiento administrativo legalmente determinado, mientras que el derecho de petición tendrá por objeto el que se dicte un acto administrativo para resolver un problema de interés particular o general, pero no es el medio adecuado para revocar o dejar sin efecto los actos administrativos, para lo cual existen los recursos administrativos respectivos.

Consideramos que el derecho de petición tampoco es un equivalente al derecho de acceso a la jurisdicción a través de acciones y recursos, ya que dicha materia está cubierta por el artículo $19 \mathrm{~N}^{\circ} 3$ en armonía con el artículo 76 de la Constitución que aseguran el derecho a la jurisdicción, todo ello reforzado por los artículos $8^{\circ}$ de la Convención Americana sobre Derechos Humanos y el artículo 14 del Pacto Internacional de Derechos Civiles y Políticos de Naciones Unidas. Por regla general en el caso de las acciones y recursos judiciales se requiere, por regla general, un interés legítimo para actuar, lo que no es necesario en el ámbito del derecho de petición, donde pueden plantearse temas de interés general como de interés particular, lo que posibilita pueda conocer cuestiones que de ninguna otra forma podría haber conocido. Ello no excluye el derecho de petición que pueden ejercer las personas respecto de los órganos del Poder Judicial $\mathrm{u}$ otros órganos jurisdiccionales en planos diferentes a los de las acciones, recursos y requerimientos. El Tribunal Constitucional ha aceptado, asimismo, que académicos de derecho público planteen sus puntos de vista sobre diversos requerimientos o recursos en trámite en dicho órgano jurisdiccional en base al derecho de petición constitucional, especialmente en la década de los ochenta del siglo pasado, ante la ausencia y suplencia de una figura más pertinente como puede ser el amicus curiae, el cual no existe en la materia.

Asimismo, el derecho de petición puede ejercerse respecto de las autoridades de los órganos colegisladores y sus órganos de trabajo, donde a través de audiencias públicas pueden conocerse los problemas, necesidades y sugerencias de las personas que lo deseen, o a través de la comisiones pueden recibirse los planteamientos que la ciudadanía desee realizar en virtud del derecho de petición, como asimismo se reciben a menudo los planteamientos de los grupos interesados o de especialistas en la ma- 
teria correspondiente. A su vez, mediante el ejercicio del derecho de petición, sea colectiva o individual, se puede dar a conocer a los parlamentos problemas de deficiencias de la administración o del gobierno, los cuales pueden llevar a conformar comisiones investigadoras en virtud de sus potestades fiscalizadoras. En estos casos como señala Álvarez Carreño, el derecho de petición cumple una función integradora de base democrática entre el órgano representativo democrático y la opinión pública o la ciudadanía ${ }^{4}$.

Este derecho se ejerce mediante una formulación escrita, existiendo así una exigencia de revestimiento documental, aun cuando en una perspectiva pro ejercicio de los derechos, debe caracterizarse por su antiformalismo y sencillez, pudiendo utilizarse cualquier medio adecuado, incluyendo los electrónicos o informáticos en la medida que pueda quedar acreditada la petición. La petición debe contener mínimamente la identificación del solicitante, su nacionalidad, el domicilio, aun cuando pueda solicitarse la confidencialidad de tales datos, además deben consignarse el objeto y el destinatario de la petición.

La autoridad debe dar cuenta de la recepción de la petición, lo que exige como elemento básico entregar al peticionante un comprobante fidedigno de la recepción de ella y su fecha.

\section{El derecho de respuesta del peticionario frente a la autoridad}

El derecho de petición incluye el deber intrínseco de la autoridad competente de recibirlo, exteriorizando tal recepción, el tenerlo en consideración y el de responder razonadamente al interesado.

Sin perjuicio de la caracterización como derecho de libertad de estatus negativo, el derecho de petición tiene también como derecho fundamental un estatus positivo, un componente esencial de exigencia jurídica frente a la autoridad o ante los poderes públicos, el que forma parte de su contenido intrínseco y de su contenido esencial y, por tanto de su protección constitucional, generando la obligación correlativa de la autoridad de recepcionarla, de examinar su contenido y de dar una respuesta material, en la que debe expresar la aceptación o rechazo de la petición ${ }^{5}$.

Es de la esencia del derecho de petición contener un petitum, una demanda de solución de un problema, una expresión de necesidades, el planteamiento de un problema de interés general, que requiere una con-

Álvarez Carreño, Santiago (1999). El derecho de petición. Estudio de los sistemas español, italiano, alemán, comunitario y estadounidense. Granada, Comares.

5 La Corte Constitucional alemana se ha referido a la materia en varios fallos desde los primeros ańos de su funcionamiento, el primero fue la sentencia de 22 de abril de 1953 (BVerfGE,2, 225), luego la sentencia de 11 de julio de 1961 (BVerfGE 13, 56) y la resolución de 15 de mayo de 1992, determinando la obligación de respuesta a las peticiones. 
creta actuación de la autoridad pública competente a través de una respuesta material al peticionario ${ }^{6}$.

Consideramos que el deber de responder las peticiones es un elemento de la esencia del derecho de petición, forma parte de su contenido intrínseco, el cual no es equivalente al derecho de opinión en materias de interés público o privado, que está consagrado en el artículo $19 \mathrm{~N}^{\circ} 12$ de la Constitución donde las emisiones de opiniones no requieren de respuesta alguna.

Tal perspectiva había sido asumida por la doctrina constitucional ya en la Carta Fundamental de 1925, la que contenía un enunciado normativo similar al actualmente contenido en el artículo $19 \mathrm{~N}^{\circ} 14$, el cual en el artículo $10 \mathrm{~N}^{\circ} 6$ disponía que la Constitución asegura a todos los habitantes de la República "el derecho a presentar peticiones a la autoridad constituida, sobre cualquier asunto de interés público o privado, sin otra limitación que la de proceder en términos respetuosos y convenientes".

En efecto, Alejandro Silva Bascuñán sostenía la obligatoriedad de la respuesta de la autoridad frente al derecho de petición, "ya que separada de tal obligación, carece de verdadera utilidad y eficacia" ". Rafael Raveau frente a la interrogante si el derecho de petición requería respuesta de la autoridad contestaba afirmativamente, "porque de lo contrario resultaría ilusorio este derecho. El peticionario tiene derecho a saber qué resultado tiene su petición; y esto implica por parte de la autoridad la obligación de dar una respuesta a la petición" ${ }^{\prime}$. La misma respuesta al problema entrega Carlos Estévez, quien se refiere al derecho de petición como "un limitado derecho de iniciativa que la Constitución reconoce a todos los ciudadanos y que envuelve la obligación correlativa del poder público a quien se dirige, de pronunciarse acerca de la petición que se formula"9.

En la doctrina actual tanto Alejandro Silva Bascuñán como Jorge Ovalle Quiroz que participaron en la Comisión de Estudios de la Nueva Constitución, mantuvieron en ella las opiniones que el derecho de peti-

Así lo entendió la Contraloría General de la República, en 1983 a través del dictamen N ${ }^{\circ}$ 951, de enero de 1983, en el que estableció que el derecho de petición "no es dable concebir su existencia sin la correspondiente obligación del funcionario requerido de contestar cuando dicha facultad sea ejercida, como lo ha señalado la jurisprudencia de esta Entidad Fiscalizadora, entre otros en los dictámenes números 66.037 de 1960; 70.768 de 1972; 47.045 de 1980; y 14.024 de 1981", ante un reclamo ante el Ministerio del Interior por no contestar sucesivas presentaciones en que un ciudadano impugnaba la expulsión del territorio nacional y la prohibición de entrada a él. La respuesta debía ser oportuna, directa o en la vía administrativa o formal a través de un documento escrito. Silva Bascuńán, Alejandro (1963). Tratado de Derecho Constitucional. Tomo II. Santiago de Chile, Jurídica de Chile, pp. 253-256.

Raveau, Rafael (1939). Tratado Elemental de Derecho Constitucional chileno y comparado. Santiago, Nascimento, p. 473.

Estévez, Carlos (1949). Elementos de Derecho constitucional chileno. Santiago de Chile, Jurídica de Chile, p. 123. 
ción requiere necesariamente respuesta. En el sentido contrario, se manifestaron Jaime Guzmán Errázuriz y Enrique Evans de la Cuadra ${ }^{10}$.

Por su parte, Hernán Molina Guaita señala sobre la materia en análisis que "aun cuando la Constitución no lo establece, parece obvio que el ejercicio de este derecho, obliga a la autoridad a contestar con oportunidad al peticionario, sea que acoja o rechace lo solicitado. Si no existiera esta obligación para la autoridad, sería inútil la consagración del derecho en la norma constitucional" 11 . Emilio Pfeffer y Mario Verdugo en el tratamiento del derecho de petición no se pronuncian sobre el derecho de respuesta ${ }^{12}$. A su vez, José Luis Cea, sobre el punto considerado señala "No aceptamos ninguna tesis denotativa, sea de excesos por los gobernados, como de custodia desmesurada de las prerrogativas de los gobernantes. Además, es tiempo suficiente ya para reconocer que el silencio de la autoridad, más allá de un plazo prudente según las circunstancias del caso, la hace incurrir en omisión negligente, siendo lógico concluir que ha consentido lo pedido. La ineficiencia o indolencia de la autoridad requerida no puede seguir perjudicando a los gobernados que se ajustan a lo exigido por la Constitución. La ley $\mathrm{N}^{\circ} 19.880$, ya citada se orienta en la dirección sugerida"13.

El derecho de petición es, asimismo, un derecho formal, ya que la autoridad solo está obligada a tramitar la petición y responderla razonadamente, pero la respuesta no implica necesariamente la satisfacción o respuesta positiva de lo solicitado por el peticionante, basta la existencia de una respuesta fundada o motivada, como asimismo, que se respete el principio de igualdad ante la ley y que no se genere una situación de diferencia arbitraria o de discriminación, prohibida por la Carta Fundamental en su artículo $19 \mathrm{~N}^{\circ} 2$. La petición por sí misma no tiene el valor jurídico de poner en acción un procedimiento, sea este administrativo, gubernativo, legislativo u otro, que podrá iniciarse solo si la autoridad competente decide acoger favorablemente la petición y desencadenar el impulso jurídico que pone en marcha el procedimiento respectivo.

\section{LOS LÍMITES DEL DERECHO DE PETICIÓN}

El texto constitucional establece como fronteras o límites del derecho, el que dicha petición se formule en términos respetuosos y convenien-

Actas Oficiales de la Comisión de Estudios de la Nueva Constitución, sesión 125 127. Ver asimismo, Evans de la CuAdra, Enrique (1986). Los derechos constitucionales. Tomo I. Santiago, Jurídica de Chile, pp. 367-379.

11 Molina Guatta, Hernán (2006). Derecho Constitucional. Santiago, LexisNexis, pp. 244-245.

12 Verdugo M., Mario; Pfeffer U., Emilio y Nogueira A., Humberto (2005). Derecho Constitucional, Tomo I. Santiago, Jurídica de Chile, pp. 280-281.

13 Cea Egaña, José Luis (2003). Derecho Constitucional Chileno. Tomo II. Santiago de Chile, Universidad Católica de Chile, p. 402. 
tes, vale decir, en forma pulcra, que no contengan insultos, vejámenes, lenguaje soez, sin perjuicio de poder contener críticas, las que pueden presentarse en lenguaje formal correcto y en forma adecuada al agente o autoridad a la cual se dirige el planteamiento respectivo, dando los argumentos, antecedentes y presentando las situaciones que requieren de conocimiento de la autoridad y de su acción con objeto de atender, acoger y en el caso que corresponda, resolver el problema planteado.

Es obvio que recibida la petición, ella puede ser declarada inadmisible cuando ella se refiera a materias que no son competencia de la autoridad respectiva o a planteamientos que no son susceptibles de ser acogidos por ser contrarios al ordenamiento jurídico o se formule en términos irrespetuosos o inconvenientes.

\section{SUJETO ACTIVO Y EJERCICIO DEL DERECHO DE PETICIÓN}

El derecho de petición lo puede ejercer cualquier persona natural o jurídica que tenga interés en plantear a la autoridad respectiva sus puntos de vistas, sugerencias, inquietudes o problemas que requieren conocimiento y atención de ella; tales personas pueden ser nacionales o extranjeras. Dichas personas pueden ser mayores de edad o no. Los jóvenes no están excluidos del ejercicio del derecho de petición, ellos pueden formular igualmente peticiones a la autoridad en la medida que planteen un petitum en términos inteligibles y razonables planteando materias de interés personal o de interés general, lo que pone de manifiesto el carácter de instrumento de integración social que constituye el derecho analizado.

El derecho de petición puede ser ejercido en forma individual o colectiva, ya que el texto constitucional no establece limitación alguna al respecto, pudiendo expresar problemas particulares o problemas de interés general. Así junto a las peticiones que pueden ser formuladas por cada individuo se encuentran las peticiones que puede formular un grupo más o menos numerosos de personas. En una petición colectiva, cada uno de los signatarios no hace otra cosa que ejercer el derecho asegurado constitucionalmente junto a otras personas, constituyendo un conjunto de peticiones individuales que tienen el mismo objeto o fin y que deben tramitarse de la misma forma que las peticiones individuales. Obviamente las peticiones colectivas tendrán un mayor impacto en la autoridad que una petición individual.

El ejercicio del derecho de petición puede plantear situaciones conflictivas o tensiones con determinadas relaciones de sujeción especial.

Así los funcionarios públicos que a través del ejercicio del derecho de petición revelen secretos que deben guardar en reserva en virtud de su relación de servicio, le podrán ser aplicables las sanciones penales o disciplinarias correspondientes, en la medida que su actuación implica la infracción de otros valores y principios constitucionales, que solo en tal 
caso específico pueden producir consecuencias perjudiciales para el peticionario.

A su vez, dentro de las situaciones de sujeción especial se encuentran los miembros en servicio activo de las Fuerzas Armadas, los cuales como cuerpos armados son obedientes y no deliberantes como precisa el artículo 101 de la Constitución, lo que limita su ejercicio del derecho de petición en lo referente a aspectos o materias político contingentes. En tal sentido debe tenerse presente que las relaciones de sujeción especial pueden afectar el ejercicio de determinados derechos, pero esta restricción debe ser en los términos estrictamente necesarios y sin afectar el contenido esencial del derecho. Elementos que debe tener presente el legislador al regular el ejercicio de tales derechos.

A su vez, en el caso de las personas privadas de libertad en cárceles o prisiones, no los priva del ejercicio de los demás derechos fundamentales que se les deben garantizar como a toda otra persona, salvo en los aspectos que sean incompatibles con su estado de reclusión, en una interpretación favor persona. En el ámbito penitenciario es donde más eficazmente puede hacerse efectivo el derecho de petición para dirigirse a las autoridades penitenciarias, a los ministros visitadores o a las demás autoridades que se considere necesario, con el objeto de que los conflictos o problemas de la vida intracarcelaria encuentren ámbitos legítimos y válidos de resolución e impedir que se transformen en situaciones de violencia siempre más difíciles de controlar y con mayores costos humanos.

\section{SUJETO PASIVO DEL DERECHO}

El sujeto pasivo del derecho de petición es cualquier autoridad del Estado, sea esta integrante de cualquiera de los órganos estatales, gobierno y administración central, administración desconcentrada o descentralizada, parlamentarios, órganos judiciales, órganos autónomos del Estado.

En todo caso, la autoridad debe ser aquella que tiene la competencia para conocer, atender y resolver la petición formulada por la persona que la haya planteado.

Consideramos que el derecho de petición puede ser ejercido también respecto de autoridades y organismos inter o supranacionales, en tales casos, el derecho en el plano nacional adquiere solo un carácter de libertad con un estatus negativo, el que impide al Estado y sus órganos poner obstáculos a las presentaciones que los ciudadanos realicen a tales órganos inter o supranacionales, como asimismo impide al Estado y sus organismos el generar perjuicios para el peticionario que ha ejercido el derecho en el plano internacional. Así, a manera ejemplar, pueden las personas dirigir peticiones a la Comisión Interamericana de Derechos Humanos cuando considere afectados sus derechos humanos o fundamentales resguardados por la Convención Americana sobre Derechos Humanos, debiendo el Es- 
tado y sus agentes abtenerse de obstaculizar o entorpecer dicho derecho, o de adoptar medidas de presión contra el peticionario.

\section{La necesaria regulación legislativa del derecho fundamental de petición}

Este derecho fundamental debe ser regulado y configurado por el legislador, en sus diversas hipótesis, lo cual no ha ocurrido aún a través de una normativa sistemática y general para las diversas autoridades, pese al tiempo transcurrido desde la normalización institucional democrática del país en 1990.

Por otra parte, la regulación legal debe respetar el contenido esencial del derecho, sin poner obstáculo ni desnaturalizar el ejercicio del derecho, de manera tal que dicha normativa no puede contentarse con un acuse de recibo y un archivo de la petición, sino que el interés jurídicamente protegido por el derecho exige una tramitación y una respuesta razonada al o los peticionarios, sin ello, el derecho de petición quedaría vacío de contenido y despojado de sentido y protección.

Dicha regulación jurídica debe explicitar necesariamente los efectos del silencio de la autoridad competente.

El legislador ha ido regulando limitadamente e incompletamente el ejercicio del derecho de petición a través de diversos cuerpos legales en el ámbito de la administración.

La Ley Orgánica Constitucional de Bases Generales de la Administración del Estado, dispone que "Los órganos del Estado actuarán de propia iniciativa en cumplimiento de sus funciones o a petición de parte cuando [...] se haga uso del derecho de petición o reclamo".

A su vez, el artículo 13 de la Ley $\mathrm{N}^{\circ} 19.593$ que modificó la Ley de Bases, relativa a la publicidad de los actos administrativos y de los documentos que le sirvan de sustento o complemento pueden ser solicitados por cualquier interesado solicitando tal documentación por escrito al jefe del servicio respectivo, el inciso $9^{\circ}$ de dicha disposición legal señala que "El jefe superior del órgano requerido debe pronunciarse sobre la petición, sea entregando la documentación solicitada o negándose a ello, dentro del plazo de cuarenta y ocho horas contados desde la formulación del requerimiento, o desde la expiración del plazo concedido al tercero afectado, en el caso previsto en el inciso séptimo".

El cuerpo legal en análisis, otorga eficacia a dicho derecho de petición de información en su artículo 14, determinando que "vencido el plazo previsto en el artículo anterior para la entrega de la documentación requerida [...] el requirente tendrá derecho a recurrir al juez de letras en lo civil del domicilio del órgano de la administración requerido, que se encuentre de turno según las reglas correspondientes, solicitando amparo al derecho consagrado en el articulo precedente". 
El legislador ha establecido así, la antijuridicidad del silencio administrativo o de la autoridad competente respectiva en este ámbito.

La Ley $\mathrm{N}^{\circ} 19.880$ de 2003 que establece las Bases de los procedimientos administrativos que rigen los actos de los órganos de la administración del Estado, regula los derechos de las personas en relación a la administración en su artículo 17, determina la capacidad para actuar en el artículo 20, identifica a los interesados en el procedimiento administrativo en el artículo 21, consigna los plazos para resolver las peticiones en el artículo 24, como asimismo norma el silencio administrativo positivo y negativo en sus artículos 64 y 65, para determinar los efectos del silencio administrativo en el artículo 66.

La Ley señala, en su artículo 17: "Derechos de las personas. Las personas, en sus relaciones con la Administración, tienen derecho a: a) Conocer, en cualquier momento, el estado de tramitación de los procedimientos en los que tengan la condición de interesados...".

El artículo 20 del mismo cuerpo legal precisa, por su parte:

"Capacidad para actuar. Tendrán capacidad de actuar ante la Administración, además de las personas que gocen de ella o la ejerzan con arreglo a las normas generales, los menores de edad para el ejercicio y defensa de aquellos de sus derechos e intereses cuya actuación esté permitida por el ordenamiento jurídico-administrativo...”.

A su vez, el artículo 21 de la misma ley indica que

"se consideran interesados en el procedimiento administrativo: 1. Quienes lo promuevan como titulares de derechos o intereses individuales o colectivos. 2. Los que, sin haber iniciado el procedimiento, tengan derechos que puedan resultar afectados por la decisión que en el mismo se adopte. 3. Aquellos cuyos intereses, individuales o colectivos, puedan resultar afectados por la resolución y se apersonen en el procedimiento en tanto no haya recaído resolución definitiva".

El artículo 24 sobre los plazos para resolver determina:

"El funcionario del organismo al que corresponda resolver, que reciba una solicitud, documento o expediente, deberá hacerlo llegar a la oficina correspondiente a más tardar dentro de las 24 horas siguientes a su recepción.

Las providencias de mero trámite deberán dictarse por quien deba hacerlo, dentro del plazo de 48 horas contados desde la recepción de la solicitud, documento o expediente.

Los informes, dictámenes $u$ otras actuaciones similares, deberán evacuarse dentro del plazo de 10 dias, contados desde la petición de la diligencia. 
Las decisiones definitivas deberán expedirse dentro de los 20 días siguientes, contados desde que, a petición del interesado, se certifique que el acto se encuentra en estado de resolverse. La prolongación injustificada de la certificación dará origen a responsabilidad administrativa".

El silencio administrativo positivo regulado en el artículo 64 determina que "Transcurrido el plazo legal para resolver acerca de una solicitud que haya originado un procedimiento, sin que la administración se pronuncie sobre ella, el interesado podrá denunciar el incumplimiento de dicho plazo ante la autoridad que debia resolver el asunto, requiriéndole una decisión acerca de su solicitud. Dicha autoridad deberá otorgar recibo de la denuncia, con expresión de su fecha, y elevar copia de ella a su superior jerárquico dentro de 24 horas.

Si la autoridad que debia resolver el asunto no se pronuncia en el plazo de cinco dias contados desde la recepción de la denuncia, la solicitud del interesado se entenderá aceptada.

En los casos del inciso precedente, el interesado podrá pedir que se certifique que su solicitud no ha sido resuelta dentro del plazo legal. Dicho certificado será expedido sin mayor trámite".

A su vez, el artículo 65 que regula el silencio negativo se refiere expresamente al derecho constitucional de petición:

"Se entenderá rechazada una solicitud que no sea resuelta dentro del plazo legal cuando ella afecta el patrimonio fiscal. Lo mismo se aplicará en los casos que la Administración actúe de oficio, cuando deba pronunciarse sobre impugnaciones o revisiones de actos administrativos o cuando se ejecute por parte de una persona el derecho de petición consagrado en el numeral 14 del artículo 19 de la Constitución Política.

En los casos del inciso precedente, el interesado podrá pedir que se certifique que su solicitud no ha sido resuelta dentro de plazo legal. El certificado se otorgará sin más trámite, entendiéndose que desde la fecha en que ha sido expedido empiezan a correr los plazos para interponer los recursos que procedan".

El artículo 66 del mismo cuerpo legal se refiere a los efectos del silencio administrativo:

"Los actos administrativos que concluyan por aplicación de las disposiciones de los artículos precedentes, tendrán los mismos efectos que aquellos que culminaren con una resolución expresa de la Administración, desde la fecha de la certificación de la misma".

Fuera del ámbito administrativo, no existe una regulación adecuada del derecho de petición ante los órganos que integran el Congreso Nacio- 
nal, en el reglamento de la Cámara de Diputados solo se hace alusión en la materia en su artículo $7^{\circ}$ inciso $2^{\circ}$, haciendo referencia a las solicitudes o memoriales que puedan dirigirse a la Cámara o sus comisiones, en conformidad con el artículo $19 \mathrm{~N}^{\circ} 14$ de la Constitución. El reglamento del Senado no establece regulación alguna sobre la materia.

En el ámbito del Poder Judicial tampoco hay una regulación adecuada de la materia, dentro del ámbito de sus respectivas competencias, fuera de los procedimientos formalizados y reglados propiamente judiciales, donde opera el principio de inexcusabilidad de la administración de justicia que explicita el artículo 76 inciso $2^{\circ}$ de la Carta Fundamental, el cual determina que "reclamada su intervención en forma legal y en negocios de su competencia, no podrán excusarse de ejercer su autoridad, ni aun por falta de ley que resuelva la contienda o asunto sometido a su decisión".

Respecto de las responsabilidades y sanciones a la infracción del deber de respuesta por parte de la autoridad competente, hay diversas disposiciones legales que la regulan. Nuestro Código Penal, en su libro II, título III, párrafo IV, artículo $158 \mathrm{~N}^{\circ} 4$, sanciona al empleado público que arbitrariamente impidiere a una persona hacer uso del derecho de petición que le garantiza la ley. Por otra parte, en el título V, párrafo XII, artículo 256, del mismo cuerpo punitivo, sanciona al empleado público que maliciosamente retardare o negare a los particulares la protección o servicio que deba dispensar conforme a la ley y los reglamentos respectivos. Finalmente, el estatuto administrativo regulado por Ley $\mathrm{N}^{\circ} 18.834$ en su artículo 78 literal e), prohíbe a los funcionarios públicos, someter a dilación o tramitación innecesaria los asuntos entregados a su conocimiento resolución, o exigir documentos o requisitos no establecidos en el ordenamiento vigente.

En nuestro ordenamiento jurídico no existe una ley que regule el derecho de petición desde la perspectiva de desarrollo del derecho de petición asegurado constitucionalmente, reconociendo su contenido esencial, determinando procedimiento, plazos de respuesta, consecuencias de a falta de respuesta, responsabilidades de la autoridad respectiva, a diferencia de otras legislaciones de nuestro continente o europeas, donde existen desarrollos legislativos específicos sobre la materia.

A diferencia del caso chileno, en el contexto europeo, considerando solo el ejemplo español, hay una ley orgánica especifica $4 / 2001^{14}$, que regula el derecho constitucional de petición respecto de todas las autoridades públicas.

Dicha ley en su artículo $1^{\circ}$ determina los titulares del derecho de petición: 
"1. Toda persona natural o jurídica, prescindiendo de su nacionalidad, puede ejercer el derecho de petición, individual o colectivamente, en los términos y con los efectos establecidos por la presente Ley y sin que su ejercicio pueda derivarse perjuicio alguno para el peticionario. No obstante no resultarán exentos de responsabilidad quienes con ocasión del ejercicio del derecho de petición incurriesen en delito o falta.

2. Los miembros de las Fuerzas o Institutos armados, o de los cuerpos sometidos s disciplina militar, solo podrán ejercer este derecho individualmente y con arreglo a lo dispuesto en la legislación especifica.

El artículo 2 de la ley, determina los destinatarios de las peticiones.

"El derecho de petición podrá ejercerse ante cualquier institución pública, administración, o autoridad, asi como ante los órganos de dirección y administración de los organismos y entidades vinculados o dependientes de las Administraciones públicas, respecto de las materias de su competencia, cualquiera que sea el ámbito territorial of funcional de esta".

El artículo 3 determina el objeto de las peticiones:

"Las peticiones podrán versar sobre cualquier asunto o materia comprendido en el ámbito de competencias del destinatario, con independencia de que afecten exclusivamente al peticionario o sean de interés colectivo general.

No son objeto de este derecho aquellas solicitudes, quejas o sugerencias para cuya satisfacción el ordenamiento juridico establezca un procedimiento especifico distinto del regulado en la presente Ley".

La ley española continúa regulando la formalización y presentación de las peticiones y su tramitación y contestación, estableciendo asimismo su protección jurisdiccional.

El artículo $11^{\circ}$ de la ley regula la respuesta que debe dar la autoridad, en parte de dicha disposición se determina:

"[...]

3. La contestación recogerá, al menos, los términos en los que la petición ha sido tomada en consideración por parte de la autoridad u órgano competente e incorporará las razones y motivos por los que se acuerda acceder a la petición o no hacerlo. En caso de que, como resultado de la petición, se haya adoptado cualquier acuerdo, medida o resolución especifica, se agregará a la contestación.

4. La autoridad u órgano competente podrá acordar, cuando lo juzgue conveniente, la inserción de la contestación en el diario oficial que corresponda.

5. Anualmente la autoridad u órgano competente confeccionará una memoria de actividades derivadas de las peticiones recibidas" 
El artículo 12 de la Ley Orgánica española precisa:

"El derecho de petición es susceptible de tutela judicial mediante las vías establecidas en el art. 53.2 de la Constitución, sin perjuicio de cualesquiera otras acciones que el peticionario estime procedentes. Podrán ser objeto de recurso contencioso-administrativo, por el procedimiento jurisdiccional de los derechos fundamentales de la persona, establecido en los arts. 114 y siguientes de la ley 29/1988, de 13 de julio, reguladora de la Jurisdicción ContenciosaAdministrativa:

a) La declaración de inadmisibilidad de la petición

b) La omisión de la obligación de contestar en el plazo establecido.

c) La ausencia en la contestación de los requisitos mínimos establecidos en el artículo anterior".

En el contexto de la Unión Europea el derecho de petición está también regulado en el Tratado de la Unión, cuyo artículo $8 \mathrm{D}$, en su párrafo primero, dispone:

"Todo ciudadano de la Unión tendrá el derecho de petición ante el Parlamento Europeo, de conformidad con lo dispuesto en el artículo 138D".

A su vez, el artículo $138 \mathrm{D}$, precisa:

"Cualquier ciudadano de la Unión, asi como cualquier persona fisica o juridica que resida o que tenga su domicilio social en un Estado miembro, tendrá derecho a presentar al Parlamento Europeo, individualmente o asociado con otros ciudadanos o personas, una petición sobre un asunto propio de los ámbitos de actuación de la comunidad que le afecte directamente".

Así el derecho de petición en la unión Europea constituye un mecanismo de relación entre los ciudadanos de la Unión y el parlamento comunitario, posibilitando el conocimiento y pronunciamiento de este último sobre diversos temas de interés comunitario de su competencia. A su vez, las peticiones de los ciudadanos al parlamento Europeo fortalecen la legitimidad de este y su peso en el análisis de las materias de competencia comunitaria ${ }^{15}$.

En el ámbito latinoamericano, por ejemplo, la Ley Orgánica de Procedimientos Administrativos de Venezuela en su artículo $2^{\circ}$ reconoce el derecho de petición asegurado constitucionalmente y lo desarrolla en el ámbito administrativo:

15 Lavilla Rubira, Juan José (1993). "El derecho de petición al parlamento Europeo", en Los derechos del europeo. Madrid, Incipit, pp. 177-187. 
"Toda persona interesada podrá, por sí o por medio de su representante, dirigir instancias o peticiones a cualquier organismo, entidad o autoridad administrativa. Estos deberán resolver las instancias o peticiones que se les dirijan o bien declarar, en su caso, los motivos que tuvieren para no hacerlo".

Derecho que está protegido por el recurso de amparo sobre Derechos y garantías Constitucionales.

En el caso del Perú, la ley respectiva, en su artículo 106, desarrolla el derecho en los siguientes términos:

"1. Cualquier administrado, individual o colectivamente, puede promover por escrito el inicio de un procedimiento administrativo ante todas y cualquiera de las entidades, ejerciendo el derecho de petición reconocido en el artículo 2 inciso 20) de la Constitución Politica del Estado.

2. El derecho de petición administrativa comprende las facultades de presentar solicitudes de interés particular del administrado, de realizar solicitudes de interés general de la colectividad, de contradecir actos administrativos, las facultades para pedir informaciones, de formular consultas y de presentar solicitudes de gracia.

3. Este derecho implica la obligación de dar al interesado una respuesta por escrito dentro del plazo legal".

En el caso de Colombia, el Código Contencioso Administrativo regula la materia en sus artículos $5^{\circ}$ a $24^{\circ}$.

\section{CONSIDERACIONES FINALES}

El derecho de petición constituye un derecho fundamental, el cual incluye intrínsecamente el derecho del peticionario a una respuesta material razonada de la autoridad competente congruente con el petitum.

El derecho de petición se encuentra insuficientemente desarrollado y regulado por el legislador respecto de diversas autoridades fuera del ámbito administrativo, lo que constituye una omisión que puede revestir el carácter de omisión inconstitucional, dado el plazo transcurrido desde la vigencia de la Carta Fundamental y la ausencia de desarrollo legislativo.

Pareciera necesario que el tema se aborde en una ley de desarrollo y regulación del derecho constitucional de petición con carácter general y que involucre a todas las autoridades estatales. 


\section{BIBLIOGRAFÍA}

- Aguerrea Mella, Pedro. "El derecho de petición ante la administración del estado: acerca de la obligación de respuesta”. En Revista Ius Publicum $N^{\circ}$ 9/2002. Escuela de Derecho, Universidad Santo Tomás. Santiago. 2002.

- Albanese, Susana. Promoción y protección internacional de los derechos humanos. Ed. La Rocca. Buenos Aires, 1992.

- Álvarez Carreño, Santiago. El derecho de petición. Estudio de los sistemas español, italiano, alemán, comunitario y estadounidense. Ed. Comares, Granada, 1999.

- Brewer-Carías, Allan. Principios de procedimiento administrativo en América Latina. Ed. Legis, Bogotá, 2003.

- Cea Egaña, José Luis. Derecho constitucional chileno. Tomo II. Ed. Universidad Católica de Chile, 2003.

- Colliard, Claude-Albert. Libertés publiques. Ed. Dalloz, Paris, 1989.

- Colom Pastor, Bartolomeu. El derecho de petición. ED. Marcial Pons y Universitat de les Illes Balears. Madrid, 1997.

- Dubourg-Lavroff, S. "Le droit de Pétition en France". Revue de Droit Public N 6, Paris, 1992.

- Evans de la Cuadra, Enrique. Los derechos constitucionales. Tomo I. Editorial Jurídica de Chile, Santiago, 1986.

- Gil-Robles, José María (Coord). Los derechos del europeo. Incipit editores, Madrid, 1993.

- Grocoli Nacci, P. Il diritto di petizione negli ordiamenti dello Stato e delle Región. Editori Jovene, Nápoles, 1979.

- González Méndez, Mario. "El derecho de petición ante la autoridad administrativa en la jurisprudencia de la Contraloría General de la República”. En Revista de Derecho Público N 37-38 enero-diciembre 1985. Facultad de derecho, Universidad de Chile, 1985.

- Jellinek, Georg. Teoría General del Estado. Ed. Maipú, Buenos Aires, 1978.

- Martínez Fernández de Velasco, Juan. Efectos del silencio administrativo positivo por parte de la administración del Estado. Ed. Dykinson, Madrid, 2003.

- Molina Guaita, Hernán. Derecho Constitucional. Ed. LexisNexis. Santiago, 2006.

- Raveau, Rafael. Tratado Elemental de Derecho Constitucional chileno y comparado. Editorial Nascimento, Santiago, 1939.

- Rossi Merighi, U. "Il diritto di petizione: Note e Spunti riconstruttivi", en Studi in Onore di Giuseppe Chiarelli, Tomo II, Giuffre editore, Milán, 1974. 
- Sánchez Freís, R. El derecho de petición y su ejercicio ante las Cámaras. Las Cortes Generales, Vol. III. Instituto de Estudios Fiscales, Madrid, 1987.

- Sánchez Morón, M. La participación del ciudadano en la Administración Pública. Ed. Centro de Estudios Constitucionales, Madrid, 1980.

- Silva Bascuñán, Alejandro. Tratado de Derecho Constitucional. Tomo II. Editorial jurídica de Chile, Santiago, 1963.

- Spagna Musso, Enrico. "Note sul diritto di petizione". Rassegna di diritto pubblico, anno XII, 1957.

- Stancati, P. "Petizione (Diritto Costituzionale)", en Enciclopedia del Diritto, Ed. Giuffre, Milan, 1983.

- Verdugo M., Mario; Pfeffer U., Emilio y Nogueira A., Humberto. Derecho Constitucional, Tomo I. Ed. Jurídica de Chile, Santiago, Reimpresión, segunda edición, 2005. 